\title{
Optimasi Konsentrasi Katalis CaO dari Cangkang Telur Ayam Negeri \\ Dalam Reaksi Transesterifikasi Minyak Jarak Pagar (Jatropha curcas L) Sebagai Bahan Biodiesel.
}

Zulmanelis Darwis, Afrizal dan Eneng Retnisa Sriutami.

Jurusan Kimia, FMIPA Universitas Negeri Jakarta, Jl pemuda No 10, Rawamangun 13220, Jakarta ,Indonesia

\begin{abstract}
Abstrak
Penelitian mengenai penggunaan katalis $\mathrm{CaO}$ dari cangkang telur pada reaksi transesterifikasi minyak jarak pagar (Jatropha curcas L) dengan metanol bertujuan untuk mendapatkan konsentrasi optimum katalis $\mathrm{CaO}$. $\mathrm{CaO}$ diperoleh dengan cara kalsinasi cangkang telur ayam negeri selama 6 jam pada suhu $800^{\circ} \mathrm{C}$. Hasil karakterisasi dengan XRD (X-Ray Diffraction) menunjukan bahwa katalis CaO hasil kalsinasi pada kondisi tersebut memiliki difraktogram yang sesuai dengan $\mathrm{CaO}$ standar. Reaksi transesterifikasi dilakukan dengan merefluks campuran minyak jarak pagar, metanol dan katalis $\mathrm{CaO}$ pada beberapa konsentrasi selama 120 menit pada suhu $60^{\circ} \mathrm{C}$. Rendemen metil ester ditentukan dengan cara menghitung jumlah gliserol yang dibebaskan dalam reaksi transesterifikasi. Dari hasil Penelitian, diketahui bahwa konsentrasi katalis CaO optimum adalah $10 \%$ (\%-w) dengan hasil metil ester sebesar $82,62 \%$ (\%-w). Uji kualitas produk menunjukan nilai densitas $\left(40^{\circ} \mathrm{C}\right) 0,86 \mathrm{~g} / \mathrm{mL}$, dan viskositas $\left(40^{\circ} \mathrm{C}\right) 11,67 \mathrm{cSt}$. serta bilangan asam 0,62 $\mathrm{mg} \mathrm{KOH} / \mathrm{g}$ minyak.
\end{abstract}

Keywords

Reaksi transesterifikasi , katalis CaO, X-Ray Diffraction,Rendemen metil ester

\section{Pendahuluan}

Menipisnya cadangan minyak bumi sebagai sumber energy mendorong untuk dilakukan diversifikasi sumber energy . Salah satu sumber energy yang telah banyak dikembangkan adalah minyak nabati atau lemak hewan. Penggunaan minyak sebagai sumber energy memiliki berbagai keuntungan antara lain bersifat terbarukan dan ramah lingkungan serta kualitas pembakaran yang baik. Banyak sumber minyak nabati yang dapat digunakan sebagai sumber energy. Namun untuk pertimbangan ekonomi, maka yang lebih menguntungkan adalah penggunaan minyak non pangan. Salah satu minyak non pangan yang mempunyai potensi besar sebagai sumber energy adalah minyak jarak [1,2,3]. Tanaman ini mampu menghasilkan minyak dengan produktivitas tinggi yaitu sekitar 30 sampai $50 \%$ berat serta mampu memproduksi buah sepanjang tahun[1].
Untuk dapat digunakan sebagai bahan bakar pengganti solar atau yang biasa disebut biodiesel, maka terhadap minyak hawani maupun nabati perlu dilakukan modifikasi untuk menyesuaikan sifat fisik maupun kimia agar sesuai dengan system pembakaran dalam mesin otomotif [4]. Modifikasi yang dilakukan adalah mengubah minyak menjadi metil ester melalui reaksi transesterifikasi [5,6]. Reaksi transesterifikasi minyak dapat dilakukan dengan katalis asam maupun basa [7]. Berdasarkan fasanya, katalis dapat digolongkan menjadi katalis homogen dan katalis heterogen [8]. Penggunaan katalis homogen kurang efektif jika dibandingkan dengan katalis heterogen, sehingga katalis heterogen lebih banyak digunakan dalam industri kimia. Katalis heterogen berpotensi digunakan kembali dan pemisahan katalis dari produk serta sisa reaktan mudah dilakukan [9]. Beberapa katalis heterogen yang telah digunakan pada produksi biodiesel, diantanya $\mathrm{MgO}, \mathrm{CaO}$, dan hydrotalcites [10]. Bahan baku untuk 
menghasilkan $\mathrm{CaO}$ umumnya $\mathrm{Ca}\left(\mathrm{NO}_{3}\right)_{2}, \mathrm{Ca}(\mathrm{OH})_{2}$ dan $\mathrm{CaCO}_{3}$. Selain itu, ada beberapa sumber kalsium alami dari limbah, seperti cangkang telur, cangkang moluska, dan tulang. Berdasarkan hasil penelitian Viriya et al katalis $\mathrm{CaO}$ dari cangkang telur mengasilkan aktivitas katalitik tertinggi pada produksi biodiesel dari minyak sawit [11]. Penggunaan cangkang telur sebagai katalis heterogen menghasilkan rendemen metil ester asam lemak lebih dari 95\% melalui reaksi transesterifikasi selama 120 menit dengan perbandingan mol minyak/ metanol 1:12. Penggunaan cangkang telur sebagai bahan baku sintesis katalis merupakan salah satu cara pemanfaatan limbah. Pada penelitian ini, akan dipelajari pengaruh konsentrasi katalis $\mathrm{CaO}$ dari limbah cangkang telur ayam negeri terhadap rendemen metil ester hasil reaksi transesterifikasi minyak jarak pagar dengan metanol.

\section{Metodologi Penelitian}

\subsection{Tujuan Penelitian}

Penelitian ini bertujuan mendapatkan konsentrasi optimum katalis $\mathrm{CaO}$ dari cangkang telur ayam dalam reaksi transesterifikasi minyak jarak pagar dan metanol. yang dilaksanakan di Laboratorium Kimia Universitas Negeri Jakarta.

\subsection{Alat Dan Bahan}

Alat-alat yang digunakan dalam penelitian ini terdiri dari: Alat Refluks dilengkapi magnetik stirrer, Alat Destilasi, Heating Mantle, Buret, Stopwatch, Piknometer, Botol timbang, Viskometer Otswald, Alat-alat gelas lain dengan spesifikasi Iwaki-Pirex, X-Ray Diffraction (XRD 6000 Simadzu).Sedangkan bahan yang dipakai adalah: minyak jarak pagar yang diproduksi perkebunan di daerah Baros (Banten), limbah cangkang telur ayam negeri yang diperoleh dari pedagang nasi goreng di Rawamangun, eter, methanol $\mathrm{MgSO}_{4}$.Serta bahan -bahan kimia untuk keperluan analisis yang diperoleh dari Merck dengan kualifikasi p.a antara lain : $\mathrm{H}_{2} \mathrm{C}_{2} \mathrm{O}_{4} \cdot 2 \mathrm{H}_{2} \mathrm{O} \mathrm{KOH}, \mathrm{NaHCO}_{3}, \mathrm{HCl} 37 \%, \mathrm{KIO}_{4}, \mathrm{KI}$
15\%, $\mathrm{Na}_{2} \mathrm{~S}_{2} \mathrm{O}_{3} .5 \mathrm{H}_{2} \mathrm{O} \mathrm{H} \mathrm{SO}_{4}, \mathrm{~K}_{2} \mathrm{Cr}_{2} \mathrm{O}_{7}$ Indikator pp dan Indikator Kanji .

\subsection{Prosedur penelitian}

Penelitian ini dilaksanakan dalam beberapa tahap yaitu:

\subsubsection{Kalsinasi cangkang telur ayam dan} karakterisasi katalis $\mathrm{CaO}[11]$.

Limbah cangkang telur dikalsinasi pada $800^{\circ} \mathrm{C}$ selama 4 dan 6 jam. Selanjutnya dilakukan karakterisasi menggunakan XRD. Katalis disimpan dalam wadah yang rapat untuk menghindari reaksi dengan udara sebelum penggunaan berikutnya.

\subsubsection{Karakterisasi minyak jarak.}

Penentuan bilangan asam dan bilangan penyabunan minyak jarak pagar awal [13]

\subsubsection{Reaksi praesterifikasi minyak jarak pagar[14] .}

Praesterifikasi minyak jarak dilakukan dengan katalis $\mathrm{H}_{2} \mathrm{SO}_{4} 0,5 \% \mathrm{~b} / \mathrm{b}$ pada suhu $60^{\circ} \mathrm{C}$ dalam labu alas datar yang dilengkapi kondensor selama 60 menit.

\subsubsection{Sintesis metil ester dengan katalis $\mathrm{CaO}$ pada berbagai konsentrasi [15]}

Sebanyak 20,0 g minyak jarak pagar dalam labu alas datar yang dilengkapi kondensor refluks diaduk pada suhu $60^{\circ} \mathrm{C}$. Kemudian ditambahkan 8,0 g metanol dan 2,5\% katalis $\mathrm{CaO}$ (b/b sampel) yang telah dipanaskan pada suhu $60^{\circ} \mathrm{C}$. Campuran direfluks selama 120 menit pada suhu $60^{\circ} \mathrm{C}$ sambil terus diaduk. Perlakuan ini diulangi untuk konsentrasi katalis $\mathrm{CaO} 5 \%, 7,5 \%, 10 \%$ dan 12,5\% (b/b sampel).

\subsubsection{Penentuan rendemen metil ester dalam produk transesterifikasi}

Rendemen metil ester ditentukan berdasarkan kadar gliserol yang dibebaskan dalam tahap transesterifikasi. Penetapan kadar gliserol dalam air dilakukan dengan metode 
titrasi iodometri [13] . Selanjutnya rendemen metil ester dihitung dengan cara tidak langsung yaitu dengan menggunakan persamaan:

Kadar Metil Ester $(\%-\mathrm{w})=\left(\right.$ mmol $\left._{\mathrm{BP}}-\mathrm{mmol}_{\mathrm{GT}}-\mathrm{mmol}_{\mathrm{BA}}\right) \times 100 \%$ mmolme.

Keterangan :

mmol $_{\mathrm{BP}}: \mathrm{mmol} \mathrm{KOH}$ untuk bilangan penyabunan

$\mathrm{mmol}_{\mathrm{GT}}: \mathrm{mmol}$ gliserol terikat

mmol $_{\text {BA }}$ : mmol bilangan asam

mmol $_{\mathrm{ME}+}: \mathrm{mmol}$ metil ester teoritis

2.3.6. Pengujian kualitas metil ester sebagai biodiesel [12]

Uji Densitas $\left(15^{\circ} \mathrm{C}\right)$ : Densitas ditentukan dengan alat Piknometer pada suhu $15{ }^{\circ} \mathrm{C}$

Uji Densitas $\left(40^{\circ} \mathrm{C}\right)$ : Sama dengan penentuan densitas pada suhu $15^{\circ} \mathrm{C}$ hanya suhunya diubah menjadi $40^{\circ}$.

Uji Viskositas $\left(40^{\circ} \mathrm{C}\right)$ : Viskositas ditentukan dengan metode Ostwald.

Uji Bilangan Asam

Sebanyak 2,0134 gram sampel dimasukkan kedalam labu erlenmeyer dan ditambahkan dengan $20 \mathrm{~mL}$ etanol 95\% netral, direfluks selama 1 jam. Selanjutnya larutan didinginkan hingga suhu ruang, kemudian ditambahkan 3 tetes indikator fenolftalein dan dilakukan titrasi dengan larutan standar $\mathrm{NaOH} 0,1 \mathrm{~N}$ hingga warna merah muda tetap (tidak berubah selam 15 detik).

Uji Bilangan Penyabunan

Sebanyak 2,0185 gram sampel dimasukkan ke dalam labu erlenmeyer $250 \mathrm{~mL}$. Kemudian ditambahkan $25 \mathrm{~mL} \mathrm{KOH}$ dalam alkohol $95 \%$ dengan menggunakan pipet gondok dan direfluks selama 1 jam sambil diaduk. Selanjutnya larutan didinginkan hingga suhu ruang dan ditambahkan tiga tetes indikator fenolftalein, kemudian dilakukan titrasi dengan larutan $\mathrm{HCl} 0,5 \mathrm{~N}$ hingga warna

larutan menjadi tak berwarna (titik akhir). Pengujian juga dilakukan untuk blanko (tanpa sampel) sebagai pembanding dan dilakukan secara duplo.

\section{Hasil Dan pembahasan}

\section{A. Kalsinasi dan Karakterisasi Katalis $\mathrm{CaO}$}

Pada proses kalsinasi akan terjadi dekomposisi termal, transisi fasa serta penghilangan fraksi-fraksi volatile. Dari penelitian sebelumnya diperoleh informasi bahwa waktu kalsinasi cangkang telur untuk menghasilkan $\mathrm{CaO}$ adalah 4 jam. Namun pada penelitian yang telah dilakukan ternyata waktu kalsinasi 4 jam belum memberi hasil yang memuaskan . Karakterisasi dengan XRD (X-Ray Diffraction) menunjukkan bahan masih mengandung $\mathrm{CaCO}_{3}$ Pola XRD katalis $\mathrm{CaO}$ hasil kalsinasi 4 jam serta perbandingan dengan pola XRD CaO standar dapat dilihat pada gambar 1 .

Untuk menyempurnakan hasil maka dilakukan kalsinasi selama 6 jam. Dan karakterisasi dengan XRD menunjukkan hasil sempurna. yang ditunjukkan dengan kesamaan pola spectrum XRD dengan $\mathrm{CaO}$ standard (gambar 2).

Katalis $\mathrm{CaO}$ hasil kalsinasi selama 6 jam berbentuk serbuk berwarna putih dengan massa sebesar $54,31 \%$ dari berat cangkang telur ayam negeri yang digunakan. Perolehan massa katalis $\mathrm{CaO}$ hasil kalsinasi dengan dua waktu yang berbeda dapat dilihat pada tabel 1 .

\section{B. Penentuan bilangan asam minyak jarak pagar}

Bilangan asam yang diperoleh pada pada sampel minyak jarak awal adalah 4,57. Dalam penggunaan katalis basa maka sampel harus mempunyai bilangan asam rendah maksimum 2 [4] . Oleh karena itu terhadap sampel terlebih dahulu dilakukan reaksi esterifikasi. (praesterifikasi), untuk menurunkan kadar asam lemak bebas yang terkandung dalam sampel [1] . 
Setelah proses praesterifikasi bilangan asam sampel turun menjadi 1,79. Proses praesterifikasi juga mengubah tampilan fisik minyak menjadi berwarna lebih cerah ( kuning kecoklatan)

\section{Transesterifikasi}

Proses transesterifikasi dengan katalis $\mathrm{CaO}$ dalam berbagai konsentrasi menghasilkan produk yang dapat dilihat pada tabel berikut

Dari tabel 2 dapat dilihat masa terbesar adalah pada penggunaan katalis sebesar $10 \%$. Namun data ini belum dapat dijadikan dasar untuk mengatakan konsentrasi optimum penggunaan katalis adalah $10 \%$. Hal ini karena produk yang dihasilkan belum dapat dipastikan seluruhnya adalah metil ester sebagai hasil reaksi. Namun masih ada kemungkinanl tercampur dengan sisa minyak yang belum mengalami reaksi transesterifikasi. Hal ini dapat terjadi karena baik minyak awal maupun metil ester sebagai produk mempunyai sifat kepolaran yang hampir sama, sehingga sulit untuk dipisahkan. Untuk menentukan konsentrasi optimum penggunaan katalis perlu dilakukan penentuan kadar metil ester yang terdapat dalam campuran produk. Konsentrasi optimum adalah konsentrasi yang menghasilkan produk paling banyak.

Dengan cara menentukan gliserol yang dihasilkan dalam reaksi transesterifikasi dapat dihitung kadar metil ester . Hasilnya ditampilkan dalam Tabel 3

\section{Kualitas Metil Ester Sebagai Biodiesel}

Kualitas metil ester sebagai biodiesel dari masing-masing produk yang dihasilkan menggunakan beberapa konsentrasi katalis $\mathrm{CaO}$ dapat dilihat pada tabel 4 .

Hasil penelitian menunjukkan , nilai viskositas produk transesterifikasi belum masuk pada rentang nilai standar viskositas biodiesel yang ditetapkan SNI. Nilai standar yang ditetapkan oleh SNI mengacu pada nilai standar Amerika Serikat (ASTM), dimana untuk uji viskositas ASTM di dasarkan pada campuran biodiesel dengan kadar metil ester $20 \%-v$ dan $80 \%-v$ solar (B-20). Oleh karena itu perlu diuji nilai viskositas campuran metil ester yang diperoleh dengan minyak solar sehingga diketahui pada campuran berapa persen metil ester yang diperoleh nilai viskositasnya masuk pada nilai standar SNI.

\section{DAFTAR PUSTAKA}

[1] Hambali, E, A. Suryani, Dadang, Hariyadi, H. Hanafie, I.K. Reksowarjojo, M. Rivai, M. Ihsanur, P. Suryadarma, S. Tjitrosemito, T.H. Soerawidjaja, T. Prawitasari, T. Prakoso, W. Purnama. 2006. Jarak Pagar Tanaman Penghasil Biodiesel. Jakarta: Penebar Swadaya.

[2] Prana, Made Sri. 2006. Budidaya Jarak (Jatropha Crucas L.), Sumber Biodiesel Menunjang Ketahanan Energi Nasional. Jakarta: Pusat Penelitian Bioteknologi, LIPI.

[3] Syah, A.N.A. 2006. Biodiesel Jarak Pagar Bahan Bakar Alternatif yang Ramah Lingkungan. Jakarta : Agro Media Pustaka.

[4] Pinto, A.C., Guarieiro, L.L.N., Rezende, M.J.C., Ribeiro, N.M., Torres, E.A., Lopes, W.A., Pereira, P.A.P., Andrade, J.B., 2005. Biodiesel: an overview. J. Braz. Chem. Soc. 16, 1313-1330.

[5] Foon, S.C. 2004. "Kinetics Study on Transesterification of Palm Oil". Journal of Oil Palm Research, Vol. 16 No.2, MPOB. 19-29.

[6] Hendartomo, T. 2006. Pemanfaatan Minyak Dari Tumbuhan Untuk Pembuatan Biodiesel. Yogyakarta.

[7] Fessenden, J. Ralph. dkk, Kimia Organik Jilid 1, Edisi Ketiga, Penerbit Erlangga, 1986. 
[8] Serio, M.D., Cozzolino, M., Giordano, M., Tesser, R., Patrono, P., Santacesaria, E., 2007. From homogeneous to heterogeneous catalysts in biodiesel production. Ind. Eng.Chem. res 46,63796384.

[9] Setyawan, D.P. 2003. "Aktivitas Katalis Cr/Zeolit dalam Reaksi Konversi Katalitik Fenol dan Metil Isobutil Keton". Jurnal IImu dasar. Vol 4. No. 2,I 70-76

[10] Liu, Y., Lotero, E., Goodwin Jr., J.G., Mo, X., 2007. "Transesterification of poultry fat with methanol using Mg-Al hydrotalcite derived catalysts". Appl. Catal. A 331, 138-148.

[11] Viriya, Empikul. N , P. Krasae , B. Puttasawat, B. Yoosuk, N. Chollacoop, aK. Faungnawakij. 2010. "Waste shells of mollusk and egg as biodiesel production catalysts". Bioresource Technology 101, 3765-3767

[12] Standar Nasional Indonesia (SNI). 2006. Standar Biodiesel Nasional. SNI Nomor : (SNI 04-71822006).

[13] Fritz, J.S. \& G.H. Schenk. 1979. Quantitative Analytical Chemistry, fourth

[14] edition. Allyn and Bacon Inc, Massachusets : 571-574.

[15] Ramadhas, A.S., S. Jayaraj, C. Muraleedharam, 2003.Use Of Vegetable Oil as I.C.Engine. Calicut:India.

[16] Freedman, B., E.H. Pryde, T.L. Mounts. 1985. "Variables Affecting the Yields of Fatty Esters from Transesterified Vegetable Oils". JAOCS. 61 (10). $130-136$.

[17] Viriya, Empikul. N , P. Krasae , B. Puttasawat, B. Yoosuk, N. Chollacoop, aK. Faungnawakij. 2010. "Waste shells of mollusk and egg as biodiesel production catalysts". Bioresource Technology 101, 3765-3767. 